\title{
EDITORIAL
}

\section{Comunicação Substantiva nas Organizações, Meio Ambiente e Pós-Burocracia: a institucionalização do Diálogo e da Confiança}

Profa. Dra. Isabella Francisca freitas Gouveia de Vasconcelos ${ }^{1}$ Prof. Dr. HÉlio ARThUR ReIS IRIgaray ${ }^{1}$

\author{
${ }^{1}$ Fundação Getulio Vargas/Escola Brasileira de Administração Pública e de EMPRESAS, Rio de Janeiro - RJ, BRASIL
}

Jean Tirole (2018), prêmio Nobel de Economia, analisa os progressos feitos em se tratando de proteção ao meio ambiente e a imperiosa necessidade de manter o aquecimento global até, no máximo, 1,5 graus centígrados. O Acordo de Paris em 2017 assinado por mais de 196 países foi um sucesso nesse sentido, fixando metas ambiciosas para que isso se torne realidade. Os países emergentes, principalmente, precisam controlar a emissão de gases de efeito estufa. Foram fixadas metas por país, com certa quantidade de gases de efeito estufa que cada um pode emitir.

Ter metas claras, Tirole (2018) propõe: limites claros aos diversos países para a emissão de carbono; auditorias para verificar se estão cumprindo estes objetivos; imposto relativo a emissão de carbono (a Suécia foi um dos primeiros países a lançar um imposto deste tipo); e um preço universal para este

\section{A proposta do Acordo de Paris é que após 2050 não haja mais emissão de gases de efeito estufa}

Em termos de comunicação, indo além da lógica política imediatista e interesseira, o Acordo de Paris foi um sucesso como exemplo de comunicação habermasiana, fixando metas tendo em vista a realidade científica dos fatos. Tal sucesso pode ser creditado ao governo de Emannuel Macron.

No entanto, como bem lembra Jean Tirole (2018), em seu livro Economics of the Common Good, é necessário que após 2050 não haja mais emissão de gases de efeito estufa. Visando atingir este objetivo, o Acordo de Paris prevê que 100 bilhões de dólares por ano serão distribuídos aos países em desenvolvimento com o fim de que sejam cumpridas metas pré-fixadas para redução da emissão dos gases de efeito estufa, sejam realizadas auditorias verdes, como acima explicado, e cobrado imposto sobre a emissão de gases de efeito estufa.

Para que este tipo de comunicação possa continuar e as medidas de inovação possam ser desenvolvidas, a humanidade precisa continuar desenvolvendo um tipo de diálogo que coloque acima de tudo os interesses do planeta e do meio ambiente e praticar, de fato, estas resoluções. A este tipo de diálogo nós denominamos diálogo de inspiração habermasiana, uma comunicação ética pragmática e democrática tendo em vista os interesses de preservação do meio ambiente e a busca por uma maior qualidade de vida para a população e justiça social.

Dessa forma, na 21a Conferência das Partes (COP21) da UNFCCC, em Paris, foi adotado um novo acordo com o objetivo central de fortalecer a resposta global à ameaça da mudança do clima e de reforçar a capacidade dos países em lidar com os impactos decorrentes dessa mudança.

\section{A Contribuição Nacionalmente Determinada (NDC) do Brasil no Contexto do Acordo de Paris}

Segundo dados da Secretaria Brasileira do Meio Ambiente, após a aprovação pelo Congresso Nacional, o Brasil concluiu, em 12 de setembro de 2016, o processo de ratificação do Acordo de Paris. No dia 21 de setembro, o instrumento foi entregue às Nações Unidas. Com isso, as metas brasileiras deixaram de ser pretendidas e tornaram-se compromissos oficiais.

A NDC do Brasil comprometeu-se a reduzir até 2025 a emissão de gases de efeito estufa em $37 \%$ abaixo dos níveis de 2005 , com uma contribuição indicativa subsequente de reduzir até 2030 a emissão de gases de efeito estufa em $43 \%$ abaixo dos níveis 
de 2005. Para isso, o país se comprometeu em aumentar a participação de bioenergia sustentável na sua matriz energética para aproximadamente $18 \%$ até 2030 , restaurar e reflorestar 12 milhões de hectares de florestas, bem como alcançar uma participação estimada de 45\% de energias renováveis na composição da matriz energética em 2030.

A NDC do Brasil corresponde a uma redução estimada em 66\% em termos de emissão de gases efeito de estufa por unidade do PIB (intensidade de emissões) em 2025 e em 75\% em termos de intensidade de emissões em 2030, ambas em relação a 2005. O Brasil, portanto, reduzirá emissões de gases de efeito estufa no contexto de um aumento contínuo da população e do PIB, bem como da renda per capita, o que confere ambição a essas metas (dados da secretaria do Meio Ambiente do Governo Federal brasileiro). Esta iniciativa mostra o sucesso do conceito de cidadania deliberativa de Habermas. Em boa parte da literatura sobre esta temática, os autores têm feito o uso do referencial habermasiano destacando a Teoria da Ação Comunicativa de Habermas. Cidadania deliberativa "[...] significa que a legitimidade das decisões políticas deve ter origem em processos de discussão, orientados pelos princípios da inclusão, do pluralismo, da igualdade participativa, da autonomia e do bem comum" (TENÓRIO, 2005, p. 105).

Em se tratando de Economia Digital, a confiança também é fundamental. Como diz Jean Tirole,

Confiança é importante, e os usuários da internet devem poder confiar no ecossistema digital. Essa confiança se aplica em duas questões: a primeira é que nos dias de hoje há muita escolha, muita informação, muitas pessoas para interagir. As plataformas estão à disposição para nos orientar e compensar nossa capacidade limitada de atenção, e isso levanta a questão sobre a confiabilidade de suas recomendações. A segunda é o problema do uso de dados pessoais. Atualmente, esses dados são ativos políticos e econômicos poderosos para quem os possui. Eles não serão sempre usados como gostaríamos que fossem, o que levanta uma complexa questão sobre direto de propriedade sobre dados (TIROLE, 2017, p. 401).

Em se tratando de confiança, o conceito de organizações pós-burocráticas, de Charles Heckscher, ou ainda de adhocracia, de Mintzberg, entre outros modelos, propõem que as formas de trabalho sejam baseadas em relações de confiança e na institucionalização da franqueza e do diálogo.

Um dos desafios colocados por Heckscher para as organizações está em desenvolver a capacidade de mobilizar pessoas com ampla diversidade de habilidades e visões para trabalhos conjuntos. Para responder a esses desafios, faz algumas distinções entre termos chaves; aborda a mudança do sistema burocrático para o de empresas colaborativas; aponta dimensões importantes da empresa como estratégias, estrutura, cultura e infraestrutura. Propõe uma abordagem transformacional, na qual a colaboração é chave e a liderança interativa orientada para a mudança, o que permite resultados superiores e compatíveis com características da era contemporânea, em que o conhecimento é o destaque.

Heckscher (2007, p. 2-5) faz algumas distinções importantes de conceitos na proposição de empresa colaborativa, na qual velocidade e sinergia entre os stakeholders (diversos agentes envolvidos num projeto, programa) são dimensões importantes para negócios baseados em conhecimento e na ideia de cooperação.

- Cooperação ocorre entre membros localmente. Esses são estáveis, as fronteiras na organização são fechadas e as habilidades homogêneas;

- Colaboração estendida ocorre quando as relações entre os membros da organização fluem e estão num processo de mudança. As fronteiras são mais flexíveis e as habilidades e capacidades de seus membros são diversas. As equipes, nesse caso, muitas vezes são compostas por colaboradores externos à organização como parceiros de negócio. As colaborações estendidas parecem mais com uma rede, com um "cluster" que estão colaborando basicamente com suas experiências e conhecimentos e nessa sinergia conseguem contribuir para um resultado superior.

- Colaboração estendida pode também ser vista como a habilidade dos indivíduos de trabalhar juntos além do escopo de pequenos grupos.

Reforçando o conceito de colaboração, Heckscher (2007, p. 2-3) afirma:

Colaborar significa trabalhar em equipe. Isso implica muito mais do que trabalhar em conjunto. Implica em um objetivo comum que não pode ser atingido sem a contribuição de todos. Isso implica processos de dialogo e negociação, troca de pontos de vista e partilha de informação e construção de racionalidades individuais para a convergência em torno do consenso. 
Esse tipo de diálogo foi necessário para a assinatura do Acordo de Paris pelas diversas nações e, nas empresas, permite a troca de informação e a colaboração para o trabalho em equipe com a confiança que rege os processos de inovação, por meio de institucionalização de diálogo franco e feedback honesto, em comunicação mais substantiva. Assim pretende fazer, por exemplo, a General Eletric em sua cultura organizacional, de acordo com posição oficial da empresa defendida na época de Jack Welch e atualmente também, visando reforçar a inovação sustentável. Institucionalizar uma cultura desse tipo também não é tarefa simples nas organizações.

Os artigos desta edição tratam de temas como jogos de negócios e processos de colaboração e competição; teoria de redes e identidade social; autonomia e justiça social em organização civil do nordeste do Brasil; a história da América Latina e o conceito de cidadania; comunidade virtual e identidade; relações de trabalho, identidade e carreira; limites do uso da força policial; mulheres gerentes e suas carreiras com filhos; inovação sustentável e empreendedorismo.

O artigo 1, "Adoção de jogo de negócios sob a perspectiva de modelo de excelência da gestão em curso de MBA: análise das avaliações multicritério por pares", de Kaizô Iwakami Beltrão e Luiz Cesar Barçante, descreve um jogo de negócios aplicado em cursos do tipo Master of Business Administration (MBA) como uma das últimas disciplinas do currículo e analisa criticamente os resultados de sua implementação em 47 turmas, envolvendo 1.410 alunos. 0 jogo de negócios tem por objetivo integrar as habilidades e competências desenvolvidas ao longo do curso e considera um sistema de avaliação com 39 quesitos baseado em um modelo de excelência que abrange todos os aspectos importantes no processo de gestão.

O artigo 2, "Teoria de Redes de Influências de Stakeholders: uma abordagem revisitada", de Fabricio Stocker, Keysa Manuela Cunha Mascena, Ana Cláudia Azevedo, João Maurício Gama Boaventura, demonstra que as interações entre múltiplos stakeholders vêm ganhando importância nas últimas décadas, dada a velocidade com que se propagam informações e se estabelecem conexões entre indivíduos e grupos. A pesquisa sobre o tema ainda carece, no entanto, de estudos empíricos que analisem o fenômeno das redes de stakeholders e da sua contribuição para o avanço da teoria.

O artigo 3, "Dar o peixe ou ensinar a pescar? 0 empoderamento como prática de inovação social em uma organização da sociedade civil", de Thaís Teles Firmino e André Gustavo Carvalho Machado, analisa o empoderamento como prática de inovação social em uma organização da sociedade civil (OSC) nordestina. Seleciona como exemplo de prática de inovação social o empoderamento de crianças e adolescentes vulneráveis socialmente.

O artigo 4, "Um ensaio sobre a história da cidadania na América Latina a partir de uma perspectiva de longo prazo", por Luciano Enrique Andrenacci, apresenta um ponto de vista sobre a história da cidadania na América Latina.

O artigo 5, "Consumo simbólico e representação do self: um estudo de interações em uma comunidade virtual de usuários Ubuntu-Br", de Osíris Luís da Cunha Fernandes, Nelson da Cruz Monteiro Fernandes, Fernando Gomes de Paiva Júnior, André Luiz Maranhão de Souza Leão e Marconi Freitas da Costa, tem como objetivo explicar como o consumo simbólico do sistema operacional Ubuntu é utilizado para a representação do self em interações na comunidade virtual Ubuntu do Brasil.

O artigo 6, "Interdependência entre redes e empresas integrantes na evolução de redes interorganizacionais", de Leander Luiz Klein e Breno Augusto Diniz Pereira, indica que a cooperação entre empresas na forma de redes pode ser considerada um mecanismo para que elas consigam os recursos que Ihes faltam. $O$ fato a ressaltar é que os recursos proporcionados pelas redes podem se tornar únicos ao longo do tempo.

0 artigo 7, "Trabalhador-consumidor: a atração de jovens pelo employer branding na escolha profissional", de Andrea Poleto Oltramari, Rosana Córdova e Maria José Tonelli, tem como objetivo discutir criticamente a importância da marca para a escolha profissional de jovens estudantes de graduação que prospectam vagas em empresas. A pesquisa se baseia no aparato conceitual contemporâneo de employer branding, consumo e estilo de vida, prosumption e cocriação.

O artigo 8, "Meteoro da ilusão: sentidos do trabalho para jovens gerentes de bancos públicos", de Elena Bandeira da Silva, Isabel de Sá Affonso da Costa, Jorge Augusto de Sá Brito e Freitas e Denise Medeiros Ribeiro Salles, apresenta resultados de pesquisa relativa ao sentido do trabalho para os jovens gerentes de bancos públicos, norteada pela Teoria das Representações Sociais. A abordagem é qualitativa, do tipo descritivo-interpretativa.

O artigo 9, "Limites do uso da força policial no Estado de São Paulo", de Samira Bueno, Renato Sérgio de Lima e Marco Antônio Carvalho Teixeira, demonstra que a polícia constitui o principal mecanismo encontrado pelo Estado moderno para garantir a manutenção da lei e da ordem, tendo como prerrogativa a regulação das relações sociais mediante força física como ato legítimo e constitutivo de sua função. 
O artigo 10, "A atuação dos burocratas de nível de rua na implementação de políticas públicas no Brasil: uma proposta de análise expandida", de Francesco Bonelli, Antonio Sérgio Araújo Fernandes, Denilson Bandeira Coêlho e Jamili da Silva Palmeira, traz uma análise sobre as múltiplas dimensões da atuação dos burocratas de nível de rua no contexto brasileiro da implementação de políticas públicas. $O$ objetivo do ensaio é contribuir para uma maior compreensão do tema com uma abordagem analítica expandida.

O artigo 11, "Cidadania deliberativa e gestão social: revisão sistemática de literatura no Brasil", de Rafael Junior dos Santos Figueiredo Salgado, Luana Ferreira dos Santos, Tamiris Cristhina Resende e Washington José de Souza, apresenta uma revisão sistemática de literatura de cidadania deliberativa e gestão social. Tem por objetivo analisar o modo como o conceito habermasiano de cidadania deliberativa é aplicado em estudos de gestão social no Brasil. Para tanto, foram consultadas as bases de dados Periódicos Capes e Google Acadêmico, usando os descritores "cidadania deliberativa" e "gestão social".

$\mathrm{O}$ artigo 12, "A construção da identidade profissional: estudo com gestoras das gerações Baby Boomers, $\mathrm{X}$ e Y", de Marlene Catarina de Oliveiras Lopes Melo, Vilma Santos Pereira Faria e Ana Lúcia Magri Lopes, tem como objetivo analisar a construção da identidade profissional de mulheres pertencentes às gerações Baby Boomers, $\mathrm{X}$ e $\mathrm{Y}$, que atuam como gerentes. Em termos metodológicos, este estudo adotou uma abordagem qualitativa-descritiva e entrevistou 32 mulheres que atuam como gerentes em diversificados setores da economia, localizados na cidade de Belo Horizonte.

O artigo 13, "Uberização do trabalho e acumulação capitalista", de David Silva Franco e Deise Luiza da Silva Ferraz, dedica-se ao avanço das forças produtivas apropriadas pelo capital, aliado ao contexto de transformação das relações socioculturais que abarcam as esferas da produção e do consumo, que tem possibilitado a ascensão do fenômeno da uberização do trabalho, termo derivado da forma de organização da empresa Uber.

O artigo 14, "A política de identidade do empreendedorismo: uma análise na perspectiva da sociologia figuracional e da psicologia social crítica", de Angelo Brigato Ésther, traz a discussão sobre a identidade articulando elementos da perspectiva crítica em psicologia social - especialmente por meio do sintagma identidade-metamorfose-emancipação desenvolvido por Antônio Ciampa -, bem como sobre o conceito de políticas de identidade.

O artigo 15, "A construção de competências coletivas na dinâmica das rotinas orçamentárias", de Samantha Luiza de Souza Broman, Roberto Lima Ruas e Sandra Regina da Rocha-Pinto, demonstra que a crescente difusão de configurações coletivas de trabalho no atual ambiente organizacional não tem apresentado contrapartida na produção científica sobre o tema.

Desejamos a todos uma excelente leitura!

Profa. Dra. Isabella francisca freitas Gouveia de Vasconcelos

PRof. DR. HÉLIo ARTHUR ReIS IRIGARAY

EDITORES 


\section{REFERÊNCIAS}

HECKSCHER, C. Google sites. [2019]. Disponível em: <https://sites. google.com/a/heckscher.us/charles-heckscher/>. Acesso em: 07 out. 2019.

HECKSCHER C.; DONNELLON, A. The post-bureaucratic organization. Thousands Oaks: Sage, 1994.

HECKSCHER, C. The Collaborative Enterprise. New Haven: Yale University Press, 2007.
TENORIO, F. Tem Razão a Administração? Ensaios de teoria organizazional. 3. ed. ljuí: Ed. Unijui, 2008. (Coleção Administração e Contabilidade).

TIROLE, J. Economics for the Common Good. Princeton: Princeton University Press, 2017.

WELCH, J. Paixão Por Vencer - A Bíblia do Sucesso. São Paulo: Campus Elsevier, 2005.

Profa. Dra. Isabella Francisca Freitas Gouveia de Vasconcelos

ORCID: https://orcid.org/0000-0001-9109-0475

Doctorat es Sciences de Gestion, HEC-Ecole des Hautes Etudes Commerciales, França (2000); Doutorado em Administração de Recursos Humanos, FGV EAESP (1997); Pós-Doutorado em Rutgers the New Jersey State University; Professora Adjunta da FGV EBAPE; Pesquisadora no CNAM - Conservatoire National D’Arts et Metiers, França. E-mail: isabella.vasconcelos@fgv.br

Prof. Dr. Hélio Arthur Reis Irigaray

ORCID: https://orcid.org/0000-0001-9580-7859

Doutor e Mestre em Administração de Empresas pela FGV EAESP e PUC-Rio, respectivamente; Bacharel em Economia pela University of Northern Iowa, EUA; Professor adjunto da FGV EBAPE e do programa CIM - Corporate International Masters, da Georgetown University, Washington, EUA; Líder do tema Diversidade e Relações de Trabalho, na linha de Gestão de Trabalho (ANPAD). E-mail: helio.irigaray@fgv.br 